\title{
Moisture content investigation in the soil samples using microwave dielectric constant measurement method
}

\author{
Shashi K. Dargar, Viranjay M. Srivastava \\ Department of Electronic Engineering, University of KwaZulu-Natal, South Africa
}

\begin{tabular}{l}
\hline Article Info \\
\hline Article history: \\
Received Jul 10, 2018 \\
Revised Sep 30, 2019 \\
Accepted Oct 7, 2019 \\
\hline
\end{tabular}

Keywords:

Dielectric constant

Emissivity

Microwave

Soil moisture

Waveguide

\begin{abstract}
The microwaves of typical frequency ranges of $3 \mathrm{GHz}$ to $30 \mathrm{GHz}$ have been in use for remote sensing applications which are progressing rapidly. The microwaves can sense existing moisture in any material that absorbs moisture such as soil or vegetation. In case of soils which may be comprised of variable mix proportionate of solids, liquids or gases and distinct textures subjected to the associated size and the arrangements of soil particles. Hence, the moisture absorption by a specific type of soil used to be different. The inherent physical and electrical properties such as color, texture, grains, dielectric constant, conductivity or permeability, etc. differentiate various soils. In this work, authors present soil moisture measurement by simple estimation of emissivity i.e. the ratio of energy radiated by an object to absorbing the body of same physical temperature. A strategic method of measuring dielectric constant using a microwave signal is used in this research work. The measurement of the dielectric constant of the soils collected from the specific regions and analysis of results has been reported. The proposed method is less complex and can further be used for the identification of soil moisture and agricultural applications.
\end{abstract}

Copyright $(2020$ Institute of Advanced Engineering and Science. All rights reserved.

\section{Corresponding Author:}

Shashi K. Dargar,

Department of Electronic Engineering, Howard College,

University of KwaZulu-Natal,

Durban, 4041, South Africa.

Email: drshashikant.dargar@ieee.org

\section{INTRODUCTION}

The soil is composed of soil particles, air, and bounded or free watering contents [1]. Microwave techniques for the measurement of soil moisture content are based on the fact that the dielectric properties of water and the soil particles are dissimilar. This emissivity is a function of physical and electrical parameters of the soiled object and related to dielectric property. The dielectric constant, which is a complex number representing the response of any material to an electric field, is the measure of dielectric properties [2, 3]. The property is about the free space $\left(\epsilon_{=} \epsilon_{\mathrm{o}} \in_{\mathrm{r}}\right)$ and involves real and imaginary components as $\epsilon=\epsilon^{\prime}+i \epsilon^{\prime \prime}$. The real part of dielectric constant $\left(\epsilon^{\prime}\right)$ is in phase and signifies the propagation characteristics of the EM signal in the material related to the wave velocity, whereas the complex component $\left(\epsilon^{\prime \prime}\right)$ is out of phase and determines the energy losses as the electromagnetic wave passes through the material [4-7]. The energy losses and absorption are referred to as dielectric loss factor [8]. The energy losses cause vibration or spin of the water molecules in soil [9].

Conceptually, the divergence in dielectric properties of water and dry soil, and the relation between Fresnel reflection coefficient and dielectric constant are the fundamentals of sensing soil moisture. For dry soil particles, the real part of the relative dielectric constant $\left(\epsilon_{r}^{\prime}\right)$ ranges between 2 to 5 , with an imaginary part $\left(\epsilon_{r}^{\prime \prime}\right)$ typically less than 0.05 [10]. In contrary, for free water, the relative dielectric constant at room temperature the real component is nearly 80 and the imaginary part is 4 [11]. As this much significant 
difference in dielectric constant lies in soil and water, it makes possible to measure soil moisture using microwaves. But as reported in the past $[12,13]$, because of water molecules absorbed into the surfaces of particles and restrained dipoles, the bounded water has a lower dielectric constant than free water confined to the aperture spaces. Besides this, the $\epsilon_{r}$ of moist soil is proportional to the number of water dipoles per unit volume, volumetric models are preferred over gravimetric [14, 15]. Several other passive methods have also been proposed in the past which does not make use of the microwave techniques but it clear in the literature that for the near-surface soil moisture content measurement, utilizing microwave method has the high efficacy due to all-weather competencies. In this research work, authors present the dielectric constant analysis of different soils using the microwave method and propose the soil moisture detection from the obtained results.

\section{METHODOLOGY}

This section describes the procedure followed to perform the soil dielectric constant measurement. Table 1 shows the list of soil samples specified with their PH and EC values [16-18] with their collect locations in Udaipur district. These samples were filled in the slot section of a structure called waveguide cell which is an essential part of this measurement utilized to expose the signal on the soil under test.

Table 1. Soil samples for dielectric constant measurement

\begin{tabular}{cccc}
\hline S.N. & Soil Sample Location & PH & EC \\
\hline 1 & RCA, Farm & 8.0 & 2.5 \\
2 & RCA, Farm & 7.55 & 2.7 \\
3 & Badgaon & 9.83 & 0.10 \\
4 & Badgaon & 9.68 & 0.47 \\
5 & Badgaon & 8.21 & 0.09 \\
6 & Fatehnagar & 9.69 & 0.21 \\
7 & Khumanpura & 9.74 & 0.30 \\
8 & Khumanpura & 9.94 & 0.38 \\
9 & Khumanpura & 9.62 & 0.16 \\
10 & Shivam & 9.48 & 0.87 \\
11 & Shivam & 9.35 & 1.94 \\
12 & Pabusar & 9.85 & 0.21 \\
13 & Padar & 9.90 & 0.15 \\
\hline
\end{tabular}

The measurement started with creating the waveguide cell using the mechanical tools on a metallic piece. The waveguide cell is a termination structure for $\mathrm{x}$-band rectangular waveguide. The soil sample under test has been placed into the designed slot. Figure 1 shows the designed structure of the waveguide cell with dimensions as length, width, and depth of the slot is $2.65 \mathrm{~cm}, 1.60 \mathrm{~cm}$, and $0.50 \mathrm{~cm}$, respectively. These dimensions are chosen in accordance with the bench component size specifications and radiation exposure [19].

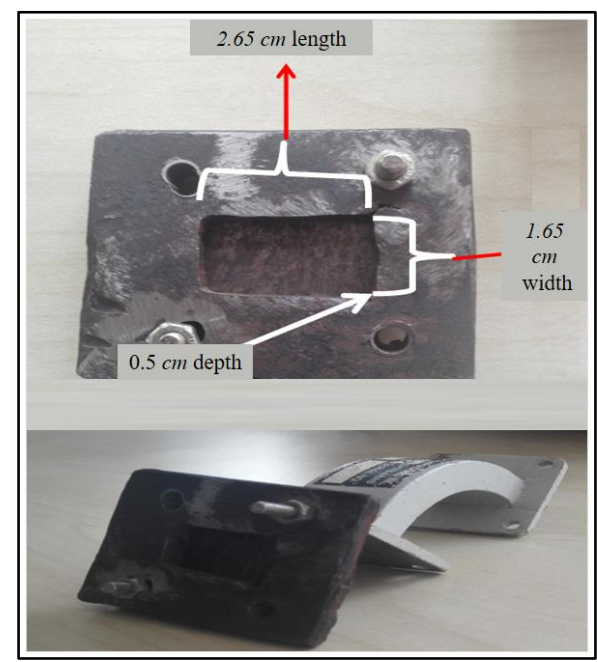

Figure 1. Designed structure for soil sample and dimensions 


\subsection{Experimental setup}

The equipment comprised of microwave bench components. This include regulated power supply to input to the microwave source, reflex klystron tube, and mount, bench isolator, microwave components, i.e. attenuator, Probe detector, short, E-H and magic tee junctions Frequency Meter, and slotted line carriage section along with measuring devices such as Voltage Standing Wave Ratio (VSWR) meter, microammeter ranges up to $500 \mu \mathrm{A}$, and oscilloscopes. The reflex klystron tube is a microwave generator with built-in feedback mechanism which functions using the single reentrant cavity for bunching and produces the output. When in operation, the initial RF fringing field of cavity modulates the velocity beam when passes through the cavity to the drift space.

The deceleration of velocity and reversal by the considerable reflector potential set up the beam to pass the cavity again in the opposite direction. Therefore, the proper choice of the reflector voltage $\left(\mathrm{V}_{\mathrm{r}}\right)$ is to be made in such a way that the phase angle adds up in the second pass of the electron beam for establishing positive feedback and to initiate the tube oscillation. The device set up is shown in Figure 2, and the alignment has been set up by connecting components and equipment as shown in the setup diagram. The variable attenuator is set to the maximum position for micrometer to indicate zero.

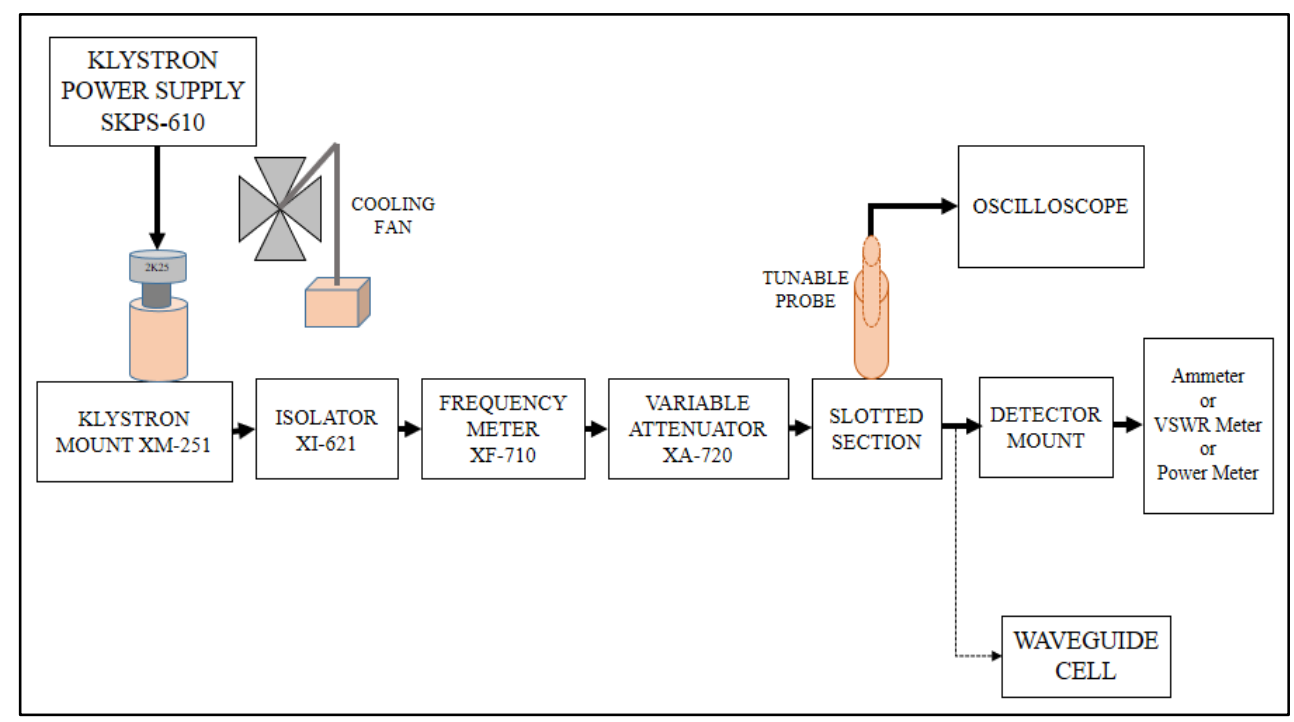

Figure 2. Experimental setup using X-band microwave bench

The mod-switch of Klystron power supply is kept to Continuous Wave (CW) position with beam voltage control knob to fully anti-clockwise and reflector voltage control knob to fully clockwise at meter switch to OFF position. Then the knob of frequency meter rotated fully at one side. Also the multimeter in DC microampere range of up to $250 \mu \mathrm{A}$. After that, once the Klystron Power Supply (KPS), VSWR meter and assisted cooling fan of the tube is switched $\mathrm{ON}$, the meter is to be switched at beam voltage position and rotated the beam voltage knob clockwise to slowly up to 300 volts. As specified for the instrument, the beam current is not being exceeded than 30 milliamps. Further, the reflector voltage $V_{r}$ is to be slightly varied to look for the fluctuation in the micrometer scales and set to the voltage point at maximum deflection in the meter. If no deflection is obtained change the multimeter switch position to $50 \mu \mathrm{A}$. and tune the plunger of Klystron mount for the maximum output. Then after the knob of frequency meter slowly revolved and stopped to a position where the output is minimum.

The direct reading of the frequency meter between two horizontal lines and the vertical marker has been marked. If micrometer type frequency meter is used, by control meter reading in the calibration chart can also give frequency at the point. For bench characteristics, the reflector voltages and read the current and frequency for each reflector voltage can be noted using an oscilloscope.

For dominant $\mathrm{TE}_{10}$ mode of a rectangular waveguide, $\lambda_{0}, \lambda_{\mathrm{g}}$, and $\lambda_{\mathrm{c}}$ are related as $[19,20]$ :

$$
\frac{1}{\left(\lambda_{o}\right)^{2}}=\frac{1}{\left(\lambda_{g}\right)^{2}}+\frac{1}{\left(\lambda_{c}\right)^{2}}
$$


where $\lambda_{\mathrm{o}}$ is free space wavelength,

$\lambda_{\mathrm{g}}$ is guided wavelength, and

$\lambda_{c}$ is cut-off wavelength

For the dominant mode $\mathrm{TE}_{10}, \lambda_{\mathrm{c}}=2 \mathrm{a}$, where ' $\mathrm{a}$ ' is the broader dimension of waveguide.

\subsection{Measuring frequency and guided wavelength}

The control knobs of klystron power supply are adjusted for alignment, as explained in Section 2.1 and then KPS, VSWR meter, and cooling fan were switched ON. The deflection with Amplitude Modulation (AM) amplitude and frequency were maximized from the control knob of power supply. The maximum deflection tuning is done for the plunger of Klystron tube and frequency meter, whereas reflector knob is kept such that few moving deflections are obtained VSWR meter. Following steps are taken to measure the frequency and guided wavelength after alignment:

a. The tunable probe is varied to get a dip on the VSWR scale and noted the frequency which is directly indicated from frequency meter.

b. The tunable probe has been shifted along the cut line in the slotted section and the deflection in VSWR meter is obtained. Now, the probe is moved to minimum deflection positions.

c. For accuracy, the VSWR meter range in $\mathrm{dB}$ has been increased to higher decibel values.

d. By rehearsing step 2, the next minimum value at the probe movement is noted.

e. Calculate the guide wavelength as twice the distance between two successive minimum positions obtained as above, as the subsequent minimums are $0.5 \lambda \mathrm{g}$ distant. The waveguide inner broad dimension ' $a$ ' which will be around $22.86 \mathrm{~mm}$ for X-band. Hence, the frequency can be calculated using the following equation [21]:

$$
f=c\left(\frac{1}{\left(\lambda_{g}\right)^{2}}+\frac{1}{\left(\lambda_{c}\right)^{2}}\right)^{1 / 2}
$$

where $c=3 \times 10^{8} \mathrm{msec}^{-1}$ i.e. velocity of light

\subsection{Measurement of dielectric constant of soil samples}

Once the frequency and guided wavelength from the set are calculated, the dielectric contact of the soil under test can be measured. This section describes the dielectric constant measurement and uses the waveguide cell placed with various soil samples in the following steps:

a. The circuit is to be set up according to the block diagram as mentioned in Figure 2. The power is applied to the source and set for warming up.

b. The frequency, RF level, and modulation of the signal source are appropriately adjusted to get the stability and maximum power output. Preferably at minimum gain $(20 \mathrm{~dB}$ or $30 \mathrm{~dB})$.

c. The $\lambda$ ga can be calculated as below:

$$
\lambda_{a}=\frac{c}{f} ; \frac{1}{\left(\lambda_{g a}\right)^{2}}=\left(\frac{1}{\lambda_{a}}\right)^{2}-\left(\frac{1}{2 \mathrm{a}}\right)^{2}
$$

where $\lambda_{a}, \lambda_{g a}$, and, a are the free space wavelength, guided wavelength, and larger dimension of the waveguide in the set up with unfilled waveguide cell.

d. At this setup frequency, three successive minima positions $\mathrm{Xa}, \mathrm{Xa}$ and $\mathrm{Xa}$ " were measured using Vernier scale of the slotted section keeping attenuation to a minimum in the microwave bench.

e. The dielectric sample soil is then introduced in the shorted waveguide cell at the same frequency and three successive minima positions $\mathrm{X} \in \mathrm{X} \in$ ' and $\mathrm{X} \in$ " were obtained.

f. The displacement or the shift ' $d$ ' in minima's of step 4 and 5 are calculated as:

$$
\mathrm{d}=\mathrm{X}_{a}-\mathrm{X}_{\epsilon}=\mathrm{X}_{a}^{\prime}-\mathrm{X}_{\epsilon}{ }^{\prime}=\mathrm{X}_{a}^{\prime \prime}-\mathrm{X}_{\epsilon}{ }^{\prime \prime}
$$

g. The tangential relation for the same unfilled and filled soil sample setup would be equal. Therefore, if the LHS term of the following equation is first calculated for $(\tan x) / x$ and then computation using the table of $\mathrm{x}$ versus $(\tan \mathrm{x}) / \mathrm{x}, \lambda \mathrm{g} \in$ can be determined [22]. 


$$
\left[\frac{\tan \left(\frac{2 \pi(\mathrm{d}+\mathrm{L})}{\lambda_{g a}}\right)}{\frac{2 \pi \mathrm{L}}{\lambda_{g a}}}\right]=\left[\frac{\tan \left(\frac{2 \pi \mathrm{L}}{\lambda_{g \in}}\right)}{\frac{2 \pi \mathrm{L}}{\lambda_{g \in}}}\right]
$$

Where $d$ is the shift in minima's of unfilled and filled waveguide cell and $\mathrm{L}$ is the length of waveguide slot.

h. $\in \mathrm{r}$ can be determined by substituting the value of $\lambda \mathrm{g} \in$ in the equation given as [22]:

$$
\epsilon_{r}=\left(\frac{\lambda_{a}}{2 a}\right)^{2}+\frac{\lambda_{a}}{\left(\lambda_{g \in}\right)^{2}}
$$

\section{EXPERIMENTAL RESULTS}

The guide wavelength has been calculated, i.e., twice of the distance between two successive minimum positions for fixed short as shown in the scales below:

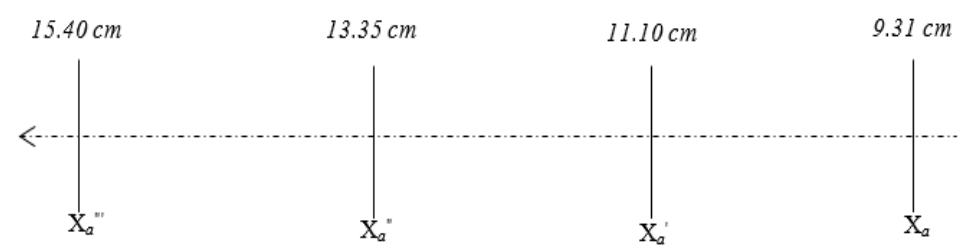

Later, the dielectric sample (soil) is introduced in the shorted waveguide cell at the same frequency and four successive minima position $\mathrm{X}_{\epsilon}, \mathrm{X}_{\epsilon}{ }^{\prime}, \mathrm{X}_{\epsilon}{ }^{\prime \prime}$, and $\mathrm{X}_{\epsilon}{ }_{\epsilon}^{\prime \prime}$ have been obtained from the measuring scale.

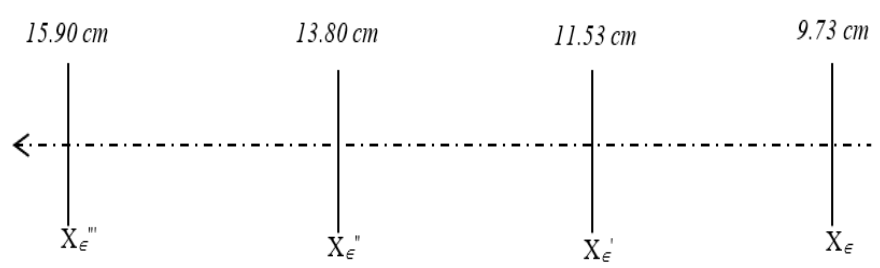

The difference in subsequent minima in the above two processes are calculated, which ideally should be the same but to obtain precision and to circumvent the observational errors, the average of the obtained difference ' $\mathrm{d}$ ' is considered.

$$
\mathbf{d}=\mathrm{X}_{a}-\mathrm{X}_{\epsilon}=\mathrm{X}_{a}^{\prime}-\mathrm{X}_{\epsilon}^{\prime}=\mathrm{X}_{a}^{\prime \prime}-\mathrm{X}_{\epsilon}{ }^{\prime \prime}
$$

The calculated values of dielectric constant measurement for the different soil samples are shown

\begin{tabular}{|c|c|c|c|c|c|c|c|c|c|c|c|c|}
\hline Soil Sample & $\begin{array}{c}\mathrm{F} \\
(G H z)\end{array}$ & $\begin{array}{c}\lambda_{\mathrm{a}} \\
(\mathrm{cm})\end{array}$ & $\begin{array}{c}\lambda_{\mathrm{ga}} \\
(\mathrm{cm})\end{array}$ & $\begin{array}{l}\mathrm{X}_{a} \\
\mathrm{X}_{\epsilon}\end{array}$ & $\begin{array}{l}\mathrm{X}_{a}^{\prime} \\
\mathrm{X}_{\epsilon}{ }^{\prime}\end{array}$ & $\begin{array}{l}\mathrm{X}_{a}{ }^{\prime \prime} \\
\mathrm{X}_{\epsilon}{ }^{\prime \prime}\end{array}$ & $\begin{array}{c}\mathrm{d}=\mathrm{X}_{a} \\
-\mathrm{X}_{\epsilon}\end{array}$ & $\begin{array}{c}\mathrm{L} \\
(\mathrm{cm})\end{array}$ & {$\left[\frac{\tan \left(\frac{2 \pi(\mathrm{d}+\mathrm{L})}{\lambda_{g a}}\right)}{\frac{2 \pi \mathrm{L}}{\lambda_{g a}}}\right.$} & $\begin{array}{c}X \text { in } \\
\tan X / \\
X\end{array}$ & $\lambda_{g \in}$ & $\epsilon_{r}$ \\
\hline RCA & 9.48 & 3.1645 & 4.08 & $\begin{array}{l}9.31 \\
9.73\end{array}$ & $\begin{array}{l}11.10 \\
11.53\end{array}$ & $\begin{array}{l}13.35 \\
13.80\end{array}$ & 0.45 & 2.65 & 0.020464 & 37.50 & 0.4437 & 5.5494 \\
\hline Badgaon & 9.48 & 3.1645 & 4.08 & $\begin{array}{l}9.16 \\
9.63\end{array}$ & $\begin{array}{l}10.95 \\
11.43\end{array}$ & $\begin{array}{l}13.20 \\
13.69\end{array}$ & 0.48 & 2.65 & 0.020708 & 38.70 & 0.4299 & 3.5946 \\
\hline Fatehnagar & 9.48 & 3.1645 & 4.08 & $\begin{array}{l}9.41 \\
9.86\end{array}$ & $\begin{array}{l}11.20 \\
11.66\end{array}$ & $\begin{array}{l}13.44 \\
13.93\end{array}$ & 0.46 & 2.65 & 0.205757 & 38.12 & 0.4365 & 4.9492 \\
\hline Padar & 9.48 & 3.1645 & 4.08 & $\begin{array}{l}9.62 \\
9.95 \\
\end{array}$ & $\begin{array}{l}11.41 \\
11.75 \\
\end{array}$ & $\begin{array}{l}13.68 \\
14.02 \\
\end{array}$ & 0.33 & 2.65 & 0.019711 & 33.50 & 0.4967 & 7.3495 \\
\hline
\end{tabular}
in Table 2.

Table 2. Calculation results of soil dielectric constants measurement 
Dielectric constant $\left(\epsilon_{r}\right)$ is a dimensionless physical quantity that reflects the ability of a substance to store polarization charge in the applied electric field. At present, the typical achievement of this method is Topp's formula [23], [24] which is an important relationship and commonly used in determining moisture content according to the dielectric constant. The Topp's formula is as follows:

$$
\begin{aligned}
& \epsilon_{r}=3.03+9.3 \Theta_{\mathrm{v}+} 146.0 \Theta_{\mathrm{v}}{ }^{2}-76.6 \Theta_{\mathrm{v}}{ }^{3} \\
& \Theta_{\mathrm{v}}=-5.3 \times 10^{2}+292 \times 10^{-2} \epsilon_{r}-5.5 \times 10^{-4} \epsilon_{r}^{2}+4.3 \times 10^{-6} \epsilon_{r}{ }^{3}
\end{aligned}
$$

where $\epsilon_{r}$ and $\Theta_{\mathrm{v}}$ are relative dielectric constant and moisture content, respectively. The radiant energy may be reflected from the surface of the dry soil, or it penetrates the soil particles, where it may be absorbed or scattered. The total reflectance from the dry soil is a function of specular reflectance and the internal volume reflectance. At increasing soil moisture, every soil particle encapsulates into a thin membrane of capillary water filling the water content in the interstitial spaces as well. That in turn results in high absorption| of incident energy following the fact that the soild reflectance deteriorates with increasing water amount [25-26].

\section{CONCLUSION AND FUTURE SCOPE}

In conclusion, the authors have presented soil moisture measurement by simple estimation of dielectric constact measurement from microwave signal. The measurement of the dielectric constant of the soils samples collected from the various regions have been used for the experiment evaluation. By measuring the dielectric constant, the measurement of moisture content of the soil can be determined. This approach can be used for identifying the need for water irrigation of a field keeping in view the availablily moisture in the soil to control unevenness. In future, the sensors and circuits using thin-film devices can be integrated to sense, monitor, and display the soil moisture and chemical status of soil [27-30]. Furthermore, this maethod of dielectric constant measure would be useful for other passive remote sensing applications as the reflectance of soil can be determined at the progression of this work.

\section{REFERENCES}

[1] N. R. Peplinski, et al., "Dielectric Properties of Soils in the 0.3-1.3-GHz Range," IEEE Transactions on Geoscience Remote Sensing, vol. 33, pp. 803-807, 1995.

[2] T. Schmugge, et al., "Passive Microwave Soil Moisture Research," IEEE Transactions on Geoscience Remote Sensing, vol. 21, pp. 12-22, 1986.

[3] J. R.Wang, et al., "An Empirical Model for the Complex Dielectric Permittivity of Soils as a Function of Water Content," IEEE Transactions on Geoscience Remote Sensing, vol. 18, pp. 288-300, 1980.

[4] T. Schmugge, Remote Sensing of Soil Moisture, Hydrological Forecasting, Wiley, 1985.

[5] G. A. Durso, et al. "The SESAR, 93 Experience on Soil Dielectric Behaviour from ERS-1 Satellite," Proceedings of the first workshop of EC-project EV5V-ct94-0446, Naples, Italy, pp. 1-13, 1994.

[6] W. Wagner, et al., "Operational readiness of microwave remote sensing of soil moisture for hydrologic applications," Hydrology Research, vol. 38, pp. 1-20, 2007.

[7] O. Bolognani, et al., "Soil Moisture Profiles from Multifrequency Radar Data at Basin Scale," Meccanica, vol. 31, pp. 59-72, 1996.

[8] S. Zegelin, "Soil Moisture Measurement," In Field Measurement Techniques in Hydrology, Workshop Notes, Cooperative Research Centre for Catchment Hydrology, Corpus Christi College, Clayton, pp. C1-C22, 1996.

[9] J. Peng, et al., "A Review of Spatial Downscaling of Satellite Remotely Sensed Soil Moisture," Reviews of Geophysics, vol. 55, pp. 341-366, 2017.

[10] F. T. Ulaby, et al., "Radar Mapping of Surface Soil Moisture," Journal of Hydrology, vol. 184, pp. 57-84, 1996.

[11] W. S. Lee, et al., "Sensing Technologies for Precision Specialty Crop Production," Computers and electronics in agriculture, vol. 74, pp. 2-33, 2010.

[12] K. Ouchi, "Recent Trend and Advance of Synthetic Aperture Radar with Selected Topics," Remote Sensing, vol. 5, pp. 716-807, 2013.

[13] J. P. Walker, et al., "Active Microwave Remote Sensing for Soil Moisture Measurement: A Field Evaluation using ERS-2," Hydrological Processes, vol. 18, pp. 1975-97, 2004.

[14] D. B. Lobell and G. P. Asner, "Moisture Effects on Soil Reflectance," Soil Science Society of America Journal, vol. 66, pp. 722-727, 2002.

[15] S. K. Dargar and V. M. Srivastava, "Retrieval of Crop Parameters by Using X-band Scatterometer Through Back Propagation Neural Network Model," International Symposium on Quantum Science and Technology, Aberdeen, UK, 24-27, 2018.

[16] M. Owe, et al., "A Methodology for Surface Soil Moisture and Vegetation Optical Depth Retrieval using the Microwave Polarization Difference Index," IEEE Transactions on Geoscience Remote Sensing, vol. 39, pp. 1643-1654, 2001.

Moisture content investigation in the soil samples using microwave dielectric constant ... (Shashi K. Dargar) 
[17] I. Lebron, et al., "The Dielectric Permittivity of Calcite and Arid Zone Soils with Carbonate Minerals," Journal of Soil Science Society of America, vol. 68, pp. 1549-1559, 2004.

[18] P. R. Chaudhari, et al., "Variation of dielectric constant of dry soils with their physical constituents and available nutrients At C-band Microwave Frequency," Journal of Chemical, Biological and Physical Sciences, vol. 2, pp. 1001, 2012.

[19] S. K. Dargar, et al., "Compact UWB antenna with T-Shaped Slots and Staircase Ground Plane for Enhanced Bandwidth," IOSR Journal of Electronics and Communication Engineering, vol. 5, pp. 12-17, 2013.

[20] D. Singh and V. M. Srivastava, "An analysis of RCS for dual-band slotted patch antenna with a thin dielectric using shorted stubs metamaterial absorber," AEU-International Journal of Electronics and Communications, vol. 90, pp. 53-62, 2018.

[21] S. Y. Liao, Microwave devices and circuits. Pearson Education, India, 1989.

[22] O. P. N. Calla, et al., "Measurement of Soil Moisture Using Microwave Radiometer," Proc. of International Conference on Recent Advances in Microwave Theory and Applications ICRAMTA, pp. 621-624, 2008.

[23] V.A. Sydoruk, et al., "Design and characterization of microwave cavity resonators for noninvasive monitoring of plant water distribution," IEEE Transactions on Microwave Theory and Techniques, vol. 64, pp. 2894-2904, 2016.

[24] X. T. Feng, et al., Rock Characterisation, Modelling, and Engineering Design Methods, CRC Press, 2013.

[25] M. Ates, M., "A review study of (bio) sensor systems based on conducting polymers," Materials Science and Engineering: $C$, vol. 33, pp. 1853-1859, 2013.

[26] Z. T. Zhu, et al., "Humidity sensors based on pentacene thin-film transistors," Applied Physics Letters, vol. 81, pp. 4643-4645, 2002.

[27] S. K. Dargar and V. M. Srivastava, "Design and analysis of novel tri-active layer channel amorphous-IGZO thin film transistor," Micro \& Nano Letters, pp. 1-5, 2019.

[28] S. K. Dargar and V. M. Srivastava, "Design and analysis of IGZO thin film transistor for AMOLED pixel circuit using double-gate tri active layer channel," Heliyon, vol. 5 no. 4, pp. e01452, 2019.

[29] H. Sharma, et al., "Soil moisture sensor calibration, actual evapotranspiration, and crop coefficients for drip irrigated greenhouse chile peppers," Agricultural Water Management, vol. 179, pp. 81-91, 2017.

[30] M. Sadeghi, et al., "A linear physically-based model for remote sensing of soil moisture using short wave infrared bands," Remote Sensing of Environment, vol. 164, pp. 66-76, 2015.

\section{BIOGRAPHIES OF AUTHORS}

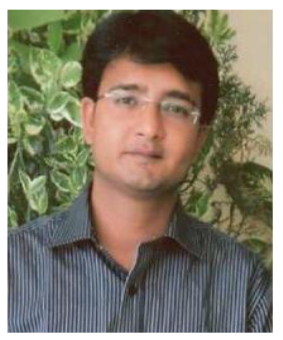

Shashi K. Dargar is presently working as a Post-Doctoral Fellow in the Department of Electronic Engineering, Howard College, University of KwaZulu-Natal, Durban, South Africa. He received his Ph.D. in Electronics Engineering, Master's degree M.Tech. in Digital Communication, and Bachelor of Engineering in Electronics and Communication Engineering. He has been contributing in the field of academics and research from the last 14 years. His research interest includes Microelectronics, Thin film device design, VLSI, Wireless Communication and Microwave Engineering. He has over 25 research articles in international journals and conferences. $\mathrm{He}$ is a member of IEEE, IACSIT, IAENG, and reviewer in various reputed international journals.

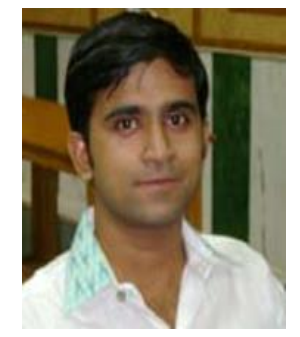

Prof. Viranjay M. Srivastava is a Doctorate (2012) in the field of RF Microelectronics and VLSI Design, Master (2008) in VLSI design, and Bachelor (2002) in Electronics and Instrumentation Engineering. He has worked for the fabrication of devices and development of circuit design. Presently, he is currently working as an Associate Professor in the Department of Electronic Engineering, Howard College, University of KwaZulu-Natal, Durban, South Africa. He has more than 15 years of teaching and research experience in the area of VLSI design, RFIC design, and Analog IC design. He has supervised various Bachelors, Masters and Doctorate theses. He is a senior member of IEEE, and member of IEEE-HKN, IITPSA, ACEEE, and IACSIT. He has worked as a reviewer for several Journals and Conferences both national and international. He is author/co-author of more than 200 scientific contributions including articles in international refereed Journals and Conferences and also author of following books, 1) VLSI Technology, 2) Characterization of C-V curves and Analysis, Using VEE Pro Software: After Fabrication of MOS Device, and 3) MOSFET Technologies for Double-Pole Four Throw Radio Frequency Switch, Springer International Publishing, Switzerland, October 2013. 